University of Nebraska - Lincoln

DigitalCommons@University of Nebraska - Lincoln

Faculty Papers and Publications in Animal

Science

Animal Science Department

2020

Beta-adrenergic agonists increase maximal output of oxidative phosphorylation in bovine satellite cells

Renae L. Sieck

Leah K. Treffer

Martonio Ponte Viana

Oleh Khalimonchuk

Ty B. Schmidt

See next page for additional authors

Follow this and additional works at: https://digitalcommons.unl.edu/animalscifacpub

Part of the Genetics and Genomics Commons, and the Meat Science Commons

This Article is brought to you for free and open access by the Animal Science Department at DigitalCommons@University of Nebraska - Lincoln. It has been accepted for inclusion in Faculty Papers and Publications in Animal Science by an authorized administrator of DigitalCommons@University of Nebraska Lincoln. 
Authors

Renae L. Sieck, Leah K. Treffer, Martonio Ponte Viana, Oleh Khalimonchuk, Ty B. Schmidt, Dustin T. Yates, and Jessica L. Petersen 


\title{
Beta-adrenergic agonists increase maximal output of oxidative phosphorylation in bovine satellite cells ${ }^{1}$
}

\author{
Renae L. Sieck, ${ }^{\dagger}$ Leah K. Treffer, ${ }^{\ddagger}$ Martonio Ponte Viana,,$"$ Oleh Khalimonchuk,, Ty B. Schmidt, ${ }^{\dagger}$ \\ Dustin T. Yates, ${ }^{\dagger}$ and Jessica L. Petersen ${ }^{\dagger, 2, \odot}$ \\ †Department of Animal Science, University of Nebraska-Lincoln, Lincoln, NE 68583-0908; ${ }^{\ddagger}$ Biology \\ Department, Nebraska Wesleyan University, Lincoln, NE 68504; and "Department of Biochemistry, University \\ of Nebraska-Lincoln, Lincoln, NE 68583-0908
}

(C) The Author(s) 2020. Published by Oxford University Press on behalf of the American Society of Animal Science.

This is an Open Access article distributed under the terms of the Creative Commons Attribution Non-Commercial License (http://creativecommons.org/licenses/by-nc/4.0/), which permits non-commercial re-use, distribution, and reproduction in any medium, provided the original work is properly cited. For commercial re-use, please contact journals.permissions@oup.com

Transl. Anim. Sci. 2020.4:S94-S97 doi: $10.1093 /$ tas/txaa112

\section{INTRODUCTION}

Beta-adrenergic agonists ( $\beta$ AA), Ractopamine $\mathrm{HCl}(\mathrm{RH})$ and Zilpaterol $\mathrm{HCl}(\mathrm{ZH})$, are FDAapproved supplements utilized in pigs and cattle to improve growth performance, carcass weight, and longissimus muscle area (Arp et al., 2014; Lean et al., 2014). Previous studies within our group have focused on understanding molecular changes in skeletal muscle due to $\beta$ AA supplementation. This work has shown that $\beta$ AA supplementation increases glucose oxidation in muscle from thermoneutral and heat-stressed lambs (Barnes et al., 2019) and in rat skeletal muscle stimulated with ZH (Cadaret et al., 2017). Skeletal muscle transcriptomics of lambs supplemented $\mathrm{ZH}$ revealed upregulation of genes associated with the callipyge phenotype of sheep (Yu et al., 2018) as well as the upregulation of mitochondrial solute carrier SLC25A25 (Kubik et al., 2018). SLC25A25 is a $\mathrm{Ca}^{2+}$ sensitive ATP $-\mathrm{Mg}^{2+} / \mathrm{P}_{\mathrm{i}}$ inner mitochondrial membrane solute transporter. Due to the role of

\footnotetext{
${ }^{1}$ This project is based on research that was partially supported by the Nebraska Agricultural Experiment Station with funding from the Hatch Multistate Research capacity funding program (accession number 1011055) from USDA National Institute of Food and Agriculture.

${ }^{2}$ Corresponding author: jessica.petersen@unl.edu

Received March 12, 2020.

Accepted July 8, 2020.
}

the mitochondria in metabolism and the results of prior transcriptomics studies, the objective of this study was to understand how $\beta \mathrm{AA}$ affect mitochondrial function of bovine skeletal muscle stem (i.e., satellite) cells. We hypothesized that $\beta \mathrm{AA}$ would improve efficiency and ATP production capacity of muscle stem cells by modifying mitochondrial function.

\section{MATERIALS AND METHODS}

This study was approved by the IACUC at the University of Nebraska-Lincoln, which is accredited by AAALAC International. Bovine skeletal muscle was obtained from four steers harvested at the USDA-inspected abattoir at the University of Nebraska-Lincoln. Yak muscle was collected from a privately owned abattoir and shipped overnight in ice-cold Belzer UW Cold Storage Solution (Preservation Solutions). Satellite cells were isolated and cryopreserved as previously described (Yates et al., 2014).

Satellite cells were thawed, suspended in complete growth media, and seeded onto a polyL-lysine and fibronectin coated Cell Culture Microplate (Agilent Technologies) at a density of 100,000 cells/well, and grown overnight. Cells were washed in XF Assay Media supplemented with $100 \mathrm{mM}$ sodium pyruvate, $200 \mathrm{mM}$ glutamine, and $2 \mathrm{M}$ glucose and incubated at $37^{\circ} \mathrm{C}$ for $1 \mathrm{~h}$. Mitochondrial function was determined 
by measuring oxygen consumption rates (OCRs) and extracellular acidification rates (ECARs) with an Agilent Seahorse XFe24 Flux Analyzer every 8 $\mathrm{m}$. Baseline respiration was measured at time points 1 to 3 (Fig. 1). Then, RH $(2 \mu \mathrm{M}), \mathrm{ZH}(0.1 \mu \mathrm{M})$, or carrier were injected into incubations (4 wells/ treatment). Baseline readings during $\beta \mathrm{AA}$ exposure were time points 4 to 6 (Fig. 1). Cells were stressed following the Seahorse XF Cell Mito Stress Test protocol. Oligomycin $(1 \mu \mathrm{M})$ was injected at time point 7 to inhibit complex $\mathrm{V}$ of the electron transport chain; readings 7 to 9 thus measure ATP-ase independent oxygen consumption. The uncoupling reagent carbonyl cyanide $p$-trifluoromethoxyphenylhydrazone (FCCP) $(1 \mu \mathrm{M})$ was injected at time point 10, which allows for uninterrupted flow of electrons through the electron transport chain. At this interval (time point 10 to 12 ) the maximal level of oxygen consumption of the cells is recorded. Lastly, rotenone/antimycin A $(0.5 \mu \mathrm{M})$ was injected (time point 13). Rotenone is a respiratory complex I inhibitor and antimycin A is a complex III inhibitor. They effectively ablate mitochondrial respiration. Protein was extracted from cells using M-PER Mammalian Protein Extraction Reagent (Thermo Fischer Scientific). A Pierce Coomassie Plus (Bradford) Assay Kit (Thermo Fischer Scientific) was used to measure protein concentration. Oxygen consumption rate and ECAR data were normalized to protein concentrations.

Wells with OCR or ECAR readings $\pm 1 \mathrm{SD}$ from the mean at all 15 time points were excluded from analysis. Technical replicates for each treatment $x$

\section{Seahorse XF Cell Mitochondrial Stress Test}

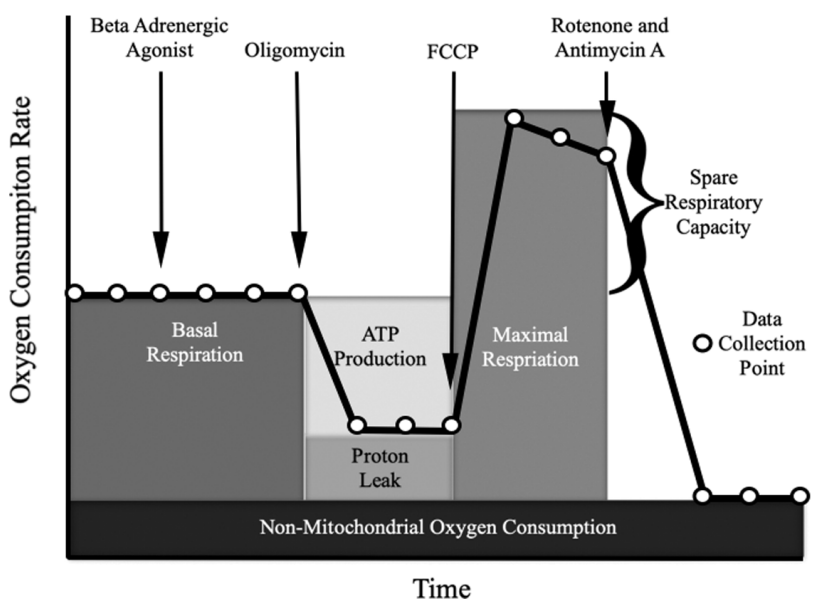

Figure 1. Experimental design for Seahorse XF Cell Mitochondrial Stress Test. Oxygen consumption rate ( $y$-axis) is measured at 15 time points (open circles) before and after the addition of $\beta$ AA (or no/control treatment) and three drugs. The expected response of the cell is shown, and measures of mitochondrial function illustrated Adapted from (Agilent Technologies, 2016). time point were averaged. Intracellular flux studies produce considerable interplate variation (Yépez et al., 2018), thus we standardized based on fold changes relative to the average baseline OCR for each sample. Mitochondrial function measures were calculated as described in Table 1 (Agilent Technologies, 2016). Treatment and animal effects were evaluated by analysis of variance using the Generalized Linear Model procedure in SAS (SAS Institute). Post hoc comparisons were evaluated with a Tukey test. Animal was the experimental unit ( $n=4$ bovine, $n=5$ total).

\section{RESULTS}

Incubation of cells with either $\mathrm{ZH}$ or $\mathrm{RH}$ increased maximal respiration $(P=0.004)$ and spare respiratory capacity $(P=0.013)$ in bovine $(n=4)$ satellite cells (Fig. 2). No difference was observed between $\mathrm{ZH}$ and $\mathrm{RH}(P>0.05)$. When the yak $(n=1)$ sample was included, maximal respiration and spare respiratory capacity were affected by both treatment $(P=0.006$ and $P=0.006$, respectively) and animal $(P=0.018$ and $P=0.009$, respectively $)$. The glycolytic capacity of $\beta$ AA-treated bovine cells did not differ from controls $(P=0.106)$. When the yak was included, glycolytic capacity still did not differ among treatments $(P=0.264)$ but an animal effect was observed $(P=0.018)$. No differences were observed among treatments or animals for non-mitochondrial respiration, basal respiration, proton leak, or ATP-linked respiration $(P>0.05$; Fig. 2). No treatment $\times$ time point produced more than one outlier, and the seven wells excluded were dispersed across plates, animals, and treatments.

\section{DISCUSSION}

In this study, we found that both $\mathrm{RH}$ and $\mathrm{ZH}$ enhance spare respiratory capacity and maximum respiration of bovine muscle stem cells. This demonstrates that $\beta \mathrm{AA}$ supplements improve the efficiency of myogenic cells by favorably modifying mitochondrial function. Ractopamine $\mathrm{HCl}$ - and $\mathrm{ZH}$-treated cells are better equipped to respond to the stress of an ATP-depleted environment than control cells due to their increased mitochondrial capacity. We postulate that this leads to better utilization of available substrates and more efficient energy production in the muscle of $\beta \mathrm{AA}$-supplemented livestock.

Previous studies have reported increased glucose oxidation in primary skeletal muscle isolated from lambs that were supplemented $\mathrm{ZH}$ (Barnes et al., 2019) and in primary rat muscle stimulated with $\mathrm{ZH}$ in vitro (Cadaret et al., 2017). Our results 
Table 1. Mitochondrial function calculations based on OCR and ECAR

\begin{tabular}{ll}
\hline \hline Measure & Calculation \\
\hline $\begin{array}{l}\text { Non-mitochondrial (mt) respiration } \\
\text { Basal respiration }\end{array}$ & $\begin{array}{l}\text { Min OCR (time point 13-15) } \\
\text { Time point 3 OCR - Non-mt } \\
\text { respiration }\end{array}$ \\
Maximal respiration & $\begin{array}{c}\text { Max OCR (time point 10-12) - } \\
\text { Non-mt respiration }\end{array}$ \\
Proton leak & Min OCR (time point 7-9) - \\
& Non-mt respiration \\
ATP-linked respiration & Time point 6 OCR - Min OCR \\
Spare respiratory capacity & (time point 7-9) \\
Glycolytic capacity & Maximal respiration - Basal \\
& respiration \\
\hline
\end{tabular}

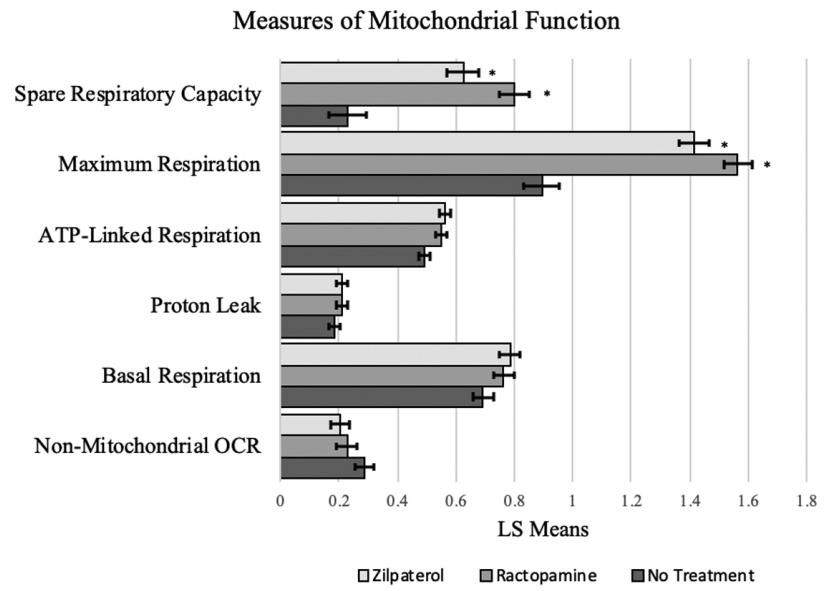

Figure 2. Least squared means ( \pm std err) for each treatment across each measurement of mitochondrial function (OCR relative to baseline time points 1 to 3$)$. ${ }^{*}$ signifies a difference $(P<0.05)$ relative to control.

indicate that $\beta \mathrm{AA}$ increased maximum, but not basal respiration rate, due to the increased intracellular availability of substrates to be oxidized. Skeletal muscle must be capable of expending high amounts of ATP to reestablish the gradient across the inner mitochondrial membrane after events that disrupt this gradient; additional available substrates would aid the mitochondria in reestablishing the ion gradient more efficiently. Uncoupling agents like FCCP can mimic the physiological energy demand typical of a muscle during exercise (Adhihetty et al., 2003). This uncoupling causes the respiratory chain to function at its maximum possible rate to reestablish the ion gradient. Rapid oxidation of substrates like sugars, fats, or amino acids is required to complete this response (Agilent Technologies, 2016). Cells treated with $\beta$ AA demonstrated an increased capacity to oxidize substrates.

Spare respiratory capacity, the difference between basal and uncoupler-stimulated respiration, reflects the cells' ability to respond to increased energy demands (Divakaruni et al., 2014). Cells with a greater spare respiratory capacity typically have decreased demands at resting states and increased mitochondrial biogenesis at different stages of the cell cycle (Divakaruni et al., 2014). Mitochondrial biogenesis in muscle is characterized by an increase in mitochondrial density in cells and increased enzyme activity within cells (Adhihetty et al., 2003). Since cells, in this study, were treated acutely with $\beta A A$ before measurement, it is unlikely that the responses were due to increased mitochondria number. Instead, it is plausible that $\beta \mathrm{AA}$ treatment is resulting in increased enzymatic activity in the oxidative phosphorylation pathway. An increase in enzymatic activity would result in more efficient ATP production in the cell, which could have implications in animal performance measures such as feed-to-gain ratios. It could also result in a decreased residual feed intake because the animal would need to consume less if their cells better utilized available nutrients. Future experiments evaluating enzyme activity are warranted to evaluate the impact on animal performance in cells treated with $\mathrm{RH}$ and $\mathrm{ZH}$.

Stimulating muscle stem cells with $\beta$ AA tended to increase ECAR $(P=0.09)$ relative to controls suggesting glycolytic capacity may be increased; this supports our previous results showing greater glucose metabolism in muscle isolated from $\beta \mathrm{AA}$-supplemented lambs (Barnes et al., 2019). This indicates that the maximum rate at which our $\beta$ AA-stimulated cells could convert glucose to pyruvate or lactate was enhanced, and a greater glycolytic capacity is indicative of a more efficient cell (Mookerjee et al., 2016). The future addition of animals to the dataset and utilization of the Seahorse XF Glycolysis Stress Test may confirm that this measure was indeed improved by $\beta A A$ treatment.

The lack of an effect of $\beta A A$ on basal respiration rates leads us to believe that $\beta \mathrm{AA}$ do not play a role in the electron transport chain of cells in a resting state. This substantiates our assertions about the cause of increased maximal respiration in $\beta \mathrm{AA}$ treated cells. In a state of rest, cell mitochondria utilize a finite amount of substrate regardless of the amount available. Therefore, we would not anticipate a difference in basal mitochondrial function between treated and untreated cells. In addition to basal respiration, $\beta \mathrm{AA}$ did not affect proton leak, non-mitochondrial respiration, or ATP-linked respiration, demonstrating no evidence of mitochondrial dysfunction, as would be suspected if proton leak was significant (Yépez et al., 2018) or there was 
a negative alteration in ATP-synthase (Divakaruni et al., 2014). This also assumes that cells had equal amounts of oxygen consumption by non-mitochondrial oxidases (Divakaruni et al., 2014).

Interestingly, the yak satellite cells were different than cattle for maximal respiration, spare respiratory capacity, and glycolytic capacity, despite also being a bovid. This could be indicative of species differences such as genomic variation or mitochondrial copy number. Future studies utilizing a greater number of yaks are warranted to determine if the observed difference holds true or if the individual used in this trial was atypical.

\section{IMPLICATIONS}

Our data indicate that both $\mathrm{ZH}$ and $\mathrm{RH}$ increase maximal respiration and spare respiratory capacity relative to controls in bovid muscle stem cells. Thus, $\beta$ AA-treated cells have indicated an increased ability to respond to cellular stresses and increased energy demands. This provides evidence that favorable modification of mitochondrial capacity is one mechanism by which $\beta A A$ supplements increase metabolic and growth efficiency of skeletal muscle in livestock. A better understanding of the mechanisms by which these supplements influence cellular function can lead to discovery of additional ways to increase livestock efficiency. Future studies will investigate potential genetic variation influencing these pathways to uncover variants that can be utilized for selection of more efficient animals.

Conflict of interest statement. None declared.

\section{LITERATURE CITED}

Adhihetty, P. J., I. Irrcher, A. M. Joseph, V. Ljubicic, and D. A. Hood. 2003. Plasticity of skeletal muscle mitochondria in response to contractile activity. Exp. Physiol. 88(1):99-107. doi:10.1113/eph8802505

Agilent Technologies. 2016. Report generator user guideAgilent Seahorse XF Cell Mito Stress Test [accessed March 03, 2020] https://www.agilent.com/cs/library/ usermanuals/public/Report_Generator_User_Guide_ Seahorse_XF_Cell_Mito_Stress_Test_Single_File.pdf.

Arp, T. S., S. T. Howard, D. R. Woerner, J. A. Scanga, D. R. McKenna, W. H. Kolath, P. L. Chapman,
J. D. Tatum, and K. E. Belk. 2014. Effects of dietary ractopamine hydrochloride and zilpaterol hydrochloride supplementation on performance, carcass traits, and carcass cutability in beef steers. J. Anim. Sci. 92(2):836-843. doi:10.2527/jas.2013-7122

Barnes, T. L., C. N. Cadaret, K. A. Beede, T. B. Schmidt, J. L. Petersen, and D. T. Yates. 2019. Hypertrophic muscle growth and metabolic efficiency were impaired by chronic heat stress, improved by zilpaterol supplementation, and not affected by ractopamine supplementation in feedlot lambs. J. Anim. Sci. 97(10):4101-4113. doi:10.1093/jas/skz271

Cadaret, C. N., K. A. Beede, H. E. Riley, and D. T. Yates. 2017. Acute exposure of primary rat soleus muscle to zilpaterol $\mathrm{HCl}$ ( $\beta 2$ adrenergic agonist), TNF $\alpha$, or IL-6 in culture increases glucose oxidation rates independent of the impact on insulin signaling or glucose uptake. Cytokine 96:107113. doi:10.1016/j.cyto.2017.03.014

Divakaruni, A. S., A. Paradyse, D. A. Ferrick, A. N. Murphy, and M. Jastroch. 2014. Analysis and interpretation of microplate-based oxygen consumption and $\mathrm{pH}$ data. Methods Enzymol. 547:309-354. doi:10.1016/ B978-0-12-801415-8.00016-3

Kubik, R. M., S. M. Tietze, T. B. Schmidt, D. T. Yates, and J. L. Petersen. 2018. Investigation of the skeletal muscle transcriptome in lambs fed $\beta$ adrenergic agonists and subjected to heat stress for $21 \mathrm{~d}$. Transl. Anim. Sci. 2(Suppl. 1):S53-S56. doi:10.1093/tas/txy053

Lean, I. J., J. M. Thompson, and F. R. Dunshea. 2014. A meta-analysis of zilpaterol and ractopamine effects on feedlot performance, carcass traits and shear strength of meat in cattle. PLoS One 9(12):e115904. doi:10.1371/ journal.pone.0115904

Mookerjee, S. A., D. G. Nicholls, and M. D. Brand. 2016. Determining maximum glycolytic capacity using extracellular flux measurements. PLoS One 11(3):e0152016. doi:10.1371/journal.pone. 0152016

Yates, D. T., D. S. Clarke, A. R. Macko, M. J. Anderson, L. A. Shelton, M. Nearing, R. E. Allen, R. P. Rhoads, and S. W. Limesand. 2014. Myoblasts from intrauterine growth-restricted sheep fetuses exhibit intrinsic deficiencies in proliferation that contribute to smaller semitendinosus myofibres. J. Physiol. 592(14):3113-3125. doi:10.1113/jphysiol.2014.272591

Yépez, V. A., L. S. Kremer, A. Iuso, M. Gusic, R. Kopajtich, E. Koňaříková, A. Nadel, L. Wachutka, H. Prokisch, and J. Gagneur. 2018. OCR-Stats: robust estimation and statistical testing of mitochondrial respiration activities using Seahorse XF Analyzer. PLoS One 13(7):e0199938. doi:10.1371/journal.pone.0199938

Yu, H., J. N. Waddell, S. Kuang, R. L. Tellam, N. E. Cockett, and C. A. Bidwell. 2018. Identification of genes directly responding to DLK1 signaling in Callipyge sheep. BMC Genomics 19(1):283. doi:10.1186/s12864-018-4682-1 